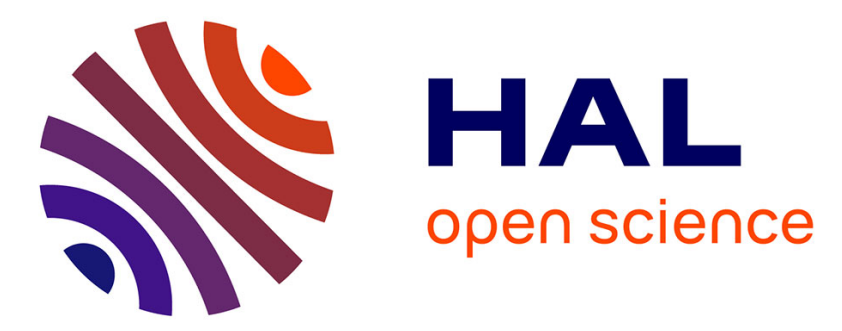

\title{
Using scattered hyperspectral imagery data to map the soil properties of a region
}

Philippe Lagacherie, Jean-Stéphane Bailly, P. Monestiez, Cecile Gomez

\section{To cite this version:}

Philippe Lagacherie, Jean-Stéphane Bailly, P. Monestiez, Cecile Gomez. Using scattered hyperspectral imagery data to map the soil properties of a region. European Journal of Soil Science, 2012, 63 (1), pp.110-119. 10.1111/j.1365-2389.2011.01409.x . hal-01522809

\section{HAL Id: hal-01522809 \\ https://hal.science/hal-01522809}

Submitted on 15 May 2017

HAL is a multi-disciplinary open access archive for the deposit and dissemination of scientific research documents, whether they are published or not. The documents may come from teaching and research institutions in France or abroad, or from public or private research centers.
L'archive ouverte pluridisciplinaire HAL, est destinée au dépôt et à la diffusion de documents scientifiques de niveau recherche, publiés ou non, émanant des établissements d'enseignement et de recherche français ou étrangers, des laboratoires publics ou privés. 


\title{
Using scattered hyperspectral imagery data to map the soil properties of a region
}

\author{
P. Lagacherie ${ }^{a}$, J. S. Bail1y ${ }^{b}$, P. Monestiez $\&$ C. Gomez ${ }^{\text {d }}$ \\ ${ }^{a}$ INRA Laboratoire d'étude des Interaction Sol Agrosystème Hydrosystème (LISAH), Campus de la Gaillarde, 2 place Viala, 34060 \\ Montpellier, France, ${ }^{\mathrm{b}}$ AgroParisTech Laboratoire d'étude des Interaction Sol Agrosystème Hydrosystème (LISAH), Campus de la \\ Gaillarde, 2 place Viala, 34060 Montpellier, France, ${ }^{\mathrm{c}}$ INRA Unité Biostatistique et Processus Spatiaux (BioSP), Domaine Saint Paul, Site \\ Agroparc, 84914 Avignon, cedex 9, France, and ${ }^{\mathrm{d} I R D}$ Laboratoire d'étude des Interaction Sol Agrosystème Hydrosystème (LISAH), \\ Campus de la Gaillarde, 2 place Viala, 34060 Montpellier, France
}

\section{Introduction}

Given the relative lack of, and huge demand for, quantitative spatial soil information to be used in environmental management and modelling, digital soil mapping (DSM) has been proposed as an alternative to classical soil surveys for the quantitative mapping of soil properties over regions at intermediate $(20-200 \mathrm{~m})$ spatial resolutions (McBratney et al., 2003). A DSM program aiming to map soil properties at global level with a 3 arc second spatial resolution has been recently launched (Sanchez et al., 2009).

McBratney et al. (2003) proposed the equation $S=f(s, c, o, r$, $p, a, n)$ for summarizing the general principle of DSM. According to this equation, a soil type or a soil property (S) can be predicted by a spatial inference function (f) using, as input, the existing soil information $(s)$, the spatial covariates that map the different factors of soil formation, as defined by Jenny (1941) ( $c, o, r$, $p, a$,), and the geographical location $(n)$, which can capture any

Correspondence: P. Lagacherie. E-mail: lagache@supagro.inra.fr

Received 4 October 2010; revised version accepted 28 September 2011 spatial trends missed by the other covariates. There has been a growing interest in using soil sensing technologies in DSM studies as a way to document $s$ (Grunwald, 2009). However, these technologies have more often been used to complement analytical soil data for individual site characterization than to produce spatial inputs of DSM models and their applications at landscape scale are even more scarce (Grunwald, 2009). Recent progress in the development of these soil sensing techniques (Ben-Dor et al., 2008; Viscarra Rossel et al., 2010), leads us to anticipate their extensive application in DSM in the near future.

Among the available soil sensors, visible near infrared (VisNIR) imaging spectrometry looks to be one of the most promising. In laboratory studies, the capability of Vis-NIR spectroscopy $(450-250 \mathrm{~nm})$ to accurately quantify soil property contents has been already proven (Viscarra Rossel et al., 2006). More recently, spatial predictions of some usual soil properties for bare soil surfaces were obtained from high-resolution airborne hyperspectral images with uncertainties ranging from $R^{2}=0.53$ to 0.75 depending on the study areas and their properties (Selige 
et al., 2006; Gomez et al., 2008; Lagacherie et al., 2008; Stevens et al., 2010; Schwanghart \& Jarmer, 2011). Although these results revealed a decrease in precision because of atmospheric effects and the signal to noise ratio (SNR) of the instrument (Lagacherie et al., 2008), imaging spectrometry provided correlations with soil properties of bare surfaces that out-performed most of the soil covariates usually considered in DSM applications. This present paper examines how this new input can be used for the DSM of soil properties over large spatial areas.

Airborne Vis-NIR imaging spectrometry differs greatly in spatial resolution and extent from those currently handled in DSM. Airborne Vis-Nir sensors provide data at very fine spatial resolutions, including less than $5 \mathrm{~m}$, which is much finer than the resolutions of the usual spatial covariates and target resolutions of DSM (see above). Also, the applications of imaging spectrometry are limited in space because of clouds and vegetation that mask the soil surface. These disruptions can result in scattered spatial data with isolated measured areas separated by non-measured areas.

To overcome these problems, we propose and test the blockco-kriging of clay content at different spatial resolutions using, as a covariate, a clay content indicator derived from an airborne hyperspectral sensor. The mapping was carried out over a $24.6-\mathrm{km}^{2}$ area located in the vineyard plain of Languedoc with usable hyperspectral data scattered over only $3.5 \%$ of this area.

\section{The case study}

\section{Study area}

The study was carried out in the La Peyne catchment (Figure 1) in the south of France $\left(43^{\circ} 29 \mathrm{~N}\right.$ and $\left.3^{\circ} 22 \mathrm{E}\right)$. Vineyards form the primary land-use in the area. Marl, limestone and calcareous sandstones from Miocene marine and lacustrine sediments formed the parent material of several soil types observed in this area, including Lithic Leptosols, Calcaric Regosols and Calcaric Cambisols (WRB soil classification, ISSS-ISRIC-FAO, 1998). These sediments were partly covered by successive alluvial deposits ranging from the Pliocene to Holocene and differing in their initial nature and in the duration of weathering conditions. These sediments have produced an intricate soil pattern that includes a large range of soil types, such as Calcaric, Chromic and Eutric Cambisols, Chromic and Eutric Luvisols and Eutric Fluvisols. The local transport of colluvial material along the slopes has added to the complexity of the soil patterns. An earlier ground sampling made in the study region (Lagacherie et al., 2008) showed that these complex soil patterns correspond to a great variability of clay content at the soil surface (from 65 to $452 \mathrm{~g} \mathrm{~kg}^{-1}$ ). A study area of $24.6 \mathrm{~km}^{2}$ (Figure 1) was defined by intersecting this region of interest with the hyperspectral image used in this study (see below).

\section{The data}

The dataset used in this study (Figure 2) included a set of 200 sites with measurements of the clay content (in $\mathrm{g} \mathrm{kg}^{-1}$ ) by means of a classical laboratory analysis (Robinson pipette) and a set

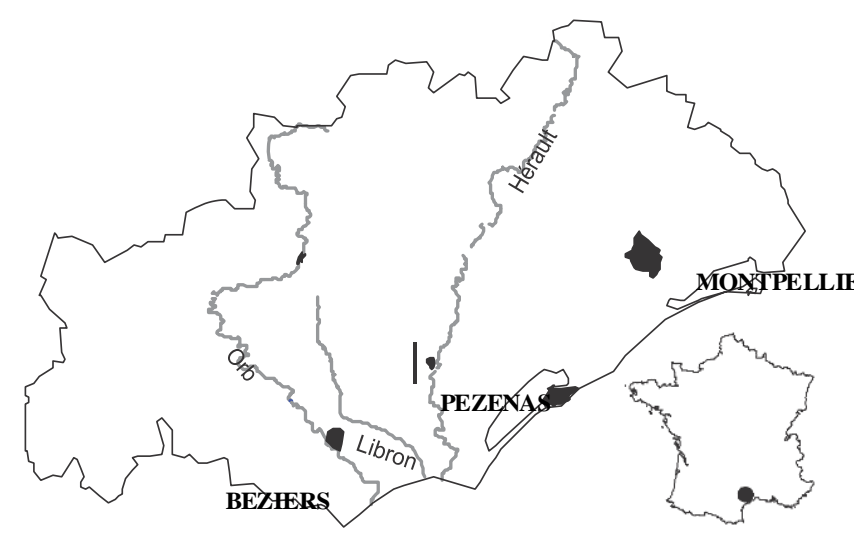

Figure 1 Location of the study area (the grey rectangle).

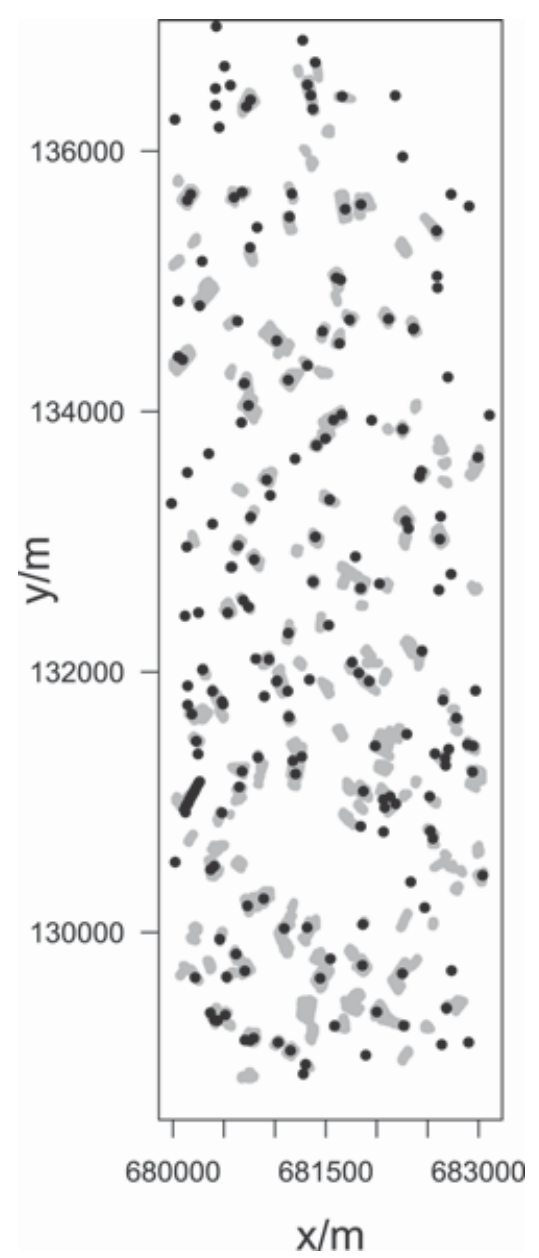

Figure 2 The sites with measurements of clay content (black dots) and the bare soil fields with estimations of clay content from the HYMAP data (grey areas).

of 192 bare soil fields with clay content estimations from a hyperspectral image that together covered 84.8 ha $(3.5 \%)$ of the study area. These two types of data are successively described in the

following. 
One hundred and thirty-seven sites of the set of 200 were located in the bare soil fields and so clay content measurements and hyperspectral estimations were available for these. The remaining 63 sites were located in vineyard areas and had clay content measurements only because the presence of vegetation prevented us from obtaining hyperspectral estimates. All of these samples were composed of five subsamples collected to a depth of $5 \mathrm{~cm}$ and representing, at best, a 5-m-wide square centred on the geographical position recorded by a decimetric GPS instrument. After homogenization of the sample and removal of plant debris and stones, about $20 \mathrm{~g}$ was used for analysis of soil properties. The initial samples were sieved and air-dried prior to transport to the laboratory for analysis.

The HYMAP airborne imaging spectrometer measured reflected radiance in 126 non-contiguous bands covering the 4002500-nm spectral range with around 19-nm bandwidths and average sampling intervals of $17 \mathrm{~nm}$ in the $1950-2480 \mathrm{~nm}$ domain (http://www.intspec.com/). The HYMAP image was acquired on 13 July 2003 from $3000-\mathrm{m}$ altitude, providing a $5 \times 5-\mathrm{m}$ spatial resolution. Radiometric calibration was performed inflight (Richter, 1996) using nadir ground measurements (Beisl, 2001). The ATCOR4 code for airborne sensors was used for atmospheric corrections (Richter \& Schläpfer, 2000). Topographic corrections were performed with a high-resolution digital elevation model from the Institut Géographique National (www.ign.fr) and differential GPS (DGPS) ground control points.

The image was masked by using normalized difference vegetation index (NDVI) to remove living vegetation (essentially vineyards). The cellulose absorption band (2010 nm) was used to remove dry vegetation. Small areas of bare soils that could not be representative of neighbouring soil characteristics were also removed. Finally, the image provided usable data over $33,7825 \times 5 \mathrm{~m}$ pixels covering $3.5 \%$ of the total area only; that is, the bare soil fields that were randomly scattered over the region at the date of measurement.

In a previous study (Lagacherie et al., 2008), a continuum removal (CR) technique (Clark \& Roush, 1984) was applied to HYMAP reflectance measurements to estimate clay contents. The clay contents were predicted from the depths of the absorption peaks at bands of $2206 \mathrm{~nm}\left(\mathrm{CR}_{2206}\right)$ that were computed as the differences between HYMAP reflectances and continua approximated by a straight line joining two local reflectance maxima placed on both shoulders of the peak absorption wavelength (see more details in Lagacherie et al., 2008). The prediction performances at local sites measured by cross-validation resulted in an $R^{2}$ value of 0.58 and a root mean square error (RMSE) of $82 \mathrm{~g} \mathrm{~kg}^{-1}$. These prediction performances were similar to those of a 1:25000 soil map in the same region (Leenhardt et al., 1994) while providing a much finer spatial resolution than a soil map at less cost. We therefore considered that $\mathrm{CR}_{2206}$ could be a suitable covariate to map clay content by DSM. To normalize the $\mathrm{CR}_{2206}$ distribution, a double log transformation was applied in further computations. This resulting variable will be denoted as $\log \log \mathrm{CR}_{2206}$.

\section{Methods}

\section{Modelling multivariate spatial correlations}

In this study, the soil variable (here, clay content) and the soil sensing covariable (here, $\log \log \mathrm{CR}_{2206}$ ) are denoted as $Z_{1}$ and $Z_{2}$, respectively. Suppose that $u$ is a location in two-dimensional space and $Z_{1}(u)$ and $Z_{2}(u)$ are spatial random functions. The random functions are assumed to satisfy the hypothesis of second-order stationarity (Matheron, 1971). Assuming that the soil variable $\left(Z_{1}\right)$ is spatially cross-correlated with the soil sensing covariable $\left(Z_{2}\right)$, the spatial cross-correlation between $Z_{1}$ and $Z_{2}$ can be quantified by a cross-covariance function or a cross-variogram as defined in Wackernagel (1995). In univariate or bivariate frameworks, the covariance and variogram functions can be estimated as follows:

$$
\hat{C} z_{i} z_{j}(h)=\frac{1}{N(\boldsymbol{h})}_{\alpha=1}^{N(\boldsymbol{h})}\left(z_{i}\left(\boldsymbol{u}_{\alpha}\right)-\bar{z}_{i}\right)\left(z_{j}\left(\boldsymbol{u}_{\alpha}+\boldsymbol{h}\right)-\bar{z}_{j}\right)
$$

and

$$
\begin{aligned}
& i j=\frac{1}{\hat{y} z} z_{\alpha=1}^{N(\boldsymbol{h})}\left(z_{i}\left(\boldsymbol{u}_{\alpha}+\boldsymbol{h}\right)-z_{i}\left(\boldsymbol{u}_{\alpha}\right)\right) \\
& \times\left(z_{j}\left(\boldsymbol{u}_{\alpha}+\boldsymbol{h}\right)-z_{j}\left(\boldsymbol{u}_{\alpha}\right)\right) \text {. }
\end{aligned}
$$

In Equations (1) and (2), $i$ and $j$ belong to $\{1,2\}$. When $i=j$, Equations (1) and (2) denote the usual covariance and variogram estimates. When $i=j$, Equations (1) and (2) denote the cross-covariance and cross-variogram estimates, respectively. $\boldsymbol{h}$ is the separation vector between the data locations $\boldsymbol{u}_{\alpha}$ and $\boldsymbol{u}_{\alpha}+\boldsymbol{h}$ (the translation of $\boldsymbol{h}$ from $\left.\boldsymbol{u}_{\alpha}\right), z_{i}\left(\boldsymbol{u}_{\alpha}\right)$ and $z_{j}\left(u_{\alpha}+\boldsymbol{h}\right.$ ) are observations of the variable $z_{i}$ and $z_{j}$ at spatial locations $\boldsymbol{u}_{\alpha}$ and $\boldsymbol{u}_{\alpha}+h$, respectively, $\bar{z}_{i}$ and $\bar{z}_{j}$ are arithmetic means of $z_{i}$ and $z_{j}$, respectively, and $N(\boldsymbol{h})$ is the number of distinct pairs of observations at distance $\boldsymbol{h}$. In the bivariate case $(i=j)$, these two expressions still have a known relationship (Wackernagel, 1995). They convey the same amount of information only if the cross-covariances are even functions. In this latter case, cross-variogram expressions are preferred for convenience, as in univariate frameworks.

To undertake the co-kriging (see later), a variogram matrix in which the diagonal entries are variograms and the off-diagonal entries are cross-variograms must be strictly conditionally negative definite. To ensure this condition, intrinsic or linear co-regionalization models can be used. The formulation of the latter in the bivariate case with two nested spatial structures is (Wackernagel, 1995)

$$
\text { (h) }=B_{1} g_{1(\boldsymbol{h})}+B_{2} g_{2(\boldsymbol{h})} \text {, }
$$

where $g_{1}(h)$ and $g_{2}(h)$ are two normalized variograms, one for each spatial structure, and $B_{1}$ and $B_{2}$ are positive semi-definite $2 \times 2$ matrices. 


\section{Co-kriging}

The co-kriging estimator is a best linear unbiased estimator (BLUE) and has minimum estimation error variance (Wackernagel, 1995). In the two variable case, the ordinary co-kriging estimator is a linear combination of weights $w_{\alpha}^{1}$ and $w_{\alpha}^{2}$ with data from the two variables $Z_{1}$ and $Z_{2}$ located at sample points in the neighbourhood of a spatial location $u_{0}$. Each variable is defined with a set of samples of possibly different sizes $n_{1}$ and $n_{2}$, and the estimator is defined as:

$$
Z_{1}\left(\boldsymbol{u}_{0}\right)={ }_{\alpha=1}^{n_{1}} w_{\alpha}^{1} Z_{1}\left(\boldsymbol{u}_{\alpha}\right)+{ }_{\alpha=1}^{n_{2}} w_{\alpha}^{2} Z_{2}\left(\boldsymbol{u}_{\alpha}\right),
$$

where the weights $w_{\alpha}^{1}$ and $w_{\alpha}^{2}$ are solutions of a co-kriging system and sum to 1 and 0 , respectively.

The co-kriging variance of the estimation error of $Z_{1}$ in the two variables case can be estimated from the variogram $\gamma_{z_{1} z_{1}}$ and the cross-variogram $\gamma_{z_{1} z_{2}}$ (Wackernagel, 1995) by using the following expression

$$
\sigma_{E}^{2}\left(\boldsymbol{u}_{0}\right)={ }_{\alpha=1}^{n_{1}}{ }^{1} w_{1 \alpha} \gamma_{z} z\left(\boldsymbol{u}_{\alpha}-\boldsymbol{u}\right)_{\alpha=1}^{n_{2}}+w_{\alpha}^{2} \gamma_{z_{1} z_{2}}\left(\boldsymbol{u}_{\alpha}-\boldsymbol{u}_{0}\right)+\mu_{z 1},
$$

where $\mu_{z_{1}}$ is the Lagrange multiplier of the co-kriging system and $\boldsymbol{u}_{\alpha}-\boldsymbol{u}_{0}$ denotes the distance between $\boldsymbol{u}_{\alpha}$ and $\boldsymbol{u}_{0}$ locations.

\section{Block co-kriging}

The predictions of the soil property $Z_{1}$ are required for the set of pixels (or square blocks) that are larger than the support of the input data. To obtain such predictions, it is possible to apply a block-ordinary co-kriging procedure (Gertner et al., 2007) that can combine and scale up the soil property measurements and the high-resolution sensing images available on a scattered set of fields. Let $v(\boldsymbol{u})$ denote a block centred at location $\boldsymbol{u}, n_{1}$ is the number of local measurements of the soil property, and $n_{2}$ is the number of the soil sensing data from the images. The ordinary co-kriging estimator for the block $v(u)$ is

$$
\hat{Z}_{1}(v(\boldsymbol{u}))={ }_{\alpha=1}^{n_{1}} \lambda_{\alpha}^{1} Z_{1}\left(\boldsymbol{u}_{\alpha}\right)+{ }_{\alpha=1}^{n_{2}} \lambda_{\alpha}^{2} Z_{2}\left(\boldsymbol{u}_{\alpha}\right),
$$

where $\lambda_{\alpha}^{1}$ and $\lambda_{\alpha}^{2}$ are the weights of the block $v(\boldsymbol{u})$ to the data. The system of equations to determine the weights in the block co-kriging estimators comes once again from the best linear unbiased estimation properties. By solving the equation system, unknown weights and the Lagrange mutiplier $\mu_{z_{1}}$ are computed. Using the solution of this system, the block co-kriging variance is calculated as:

$$
\sigma_{z 1}^{2}(v(\boldsymbol{u}))=-\mu_{z_{1}}-\gamma_{z_{1} z_{1}}(v(\boldsymbol{u}), v(\boldsymbol{u}))+{ }^{2\left(n_{i}\right)} \gamma_{z_{1} z_{j}}\left(\boldsymbol{u}_{\alpha}, v(\boldsymbol{u})\right),
$$

$$
j=1 \alpha=1
$$

where $\gamma_{z_{1} z_{1}}(v(\boldsymbol{u}), v(\boldsymbol{u}))$ is the mean within block semi-variance and it is approximated by the arithmetic average of the variogram between any two discretised points within the block $v(\boldsymbol{u})$. To simplify the notation, it is further denoted $\bar{\gamma}(v, v)$. Then, $\gamma_{z_{1} z_{j}}\left(\boldsymbol{u}_{\alpha}, v(\boldsymbol{u})\right)$ is the variogram $(\boldsymbol{j}=1)$ or cross-variogram $(j=2)$ between the data support $u_{\alpha}$ and the block $v(\boldsymbol{u})$, and it is approximated by the arithmetic average of the variogram between the data support and the points discretising the block $v(\boldsymbol{u})$.

\section{Validation procedure}

A true validation of the above procedure would ideally require us to collect composite soil samples to estimate the within-pixel mean values of the soil property over a sufficient number of locations to represent the variations of these mean values satisfactorily over the study area. A single composite soil sample requires several initial samples; for example, 25 initial samples for the $20 \times 20 \mathrm{~m}$ sites of the French National Soil Quality Monitoring Network (Jolivet et al., 2006). Thus several hundred initial samples would have to be collected for validation only, which would lead to sampling densities that are rarely possible in DSM studies. An alternative to this purely experimental validation method was therefore undertaken to verify that the approach provided a reasonable approximation of the ground truth. We first cross-validated the co-regionalization model by applying an exact ordinary co-kriging and verifying that the co-kriging error variances were correctly predicted over the study area. We thus assume that correctly predicted punctual co-kriging errors prevent incorrectly estimated model parameters, especially those for nugget values. With limitations from this assumed model parameter, we considered the block co-kriging error variances were correctly predicted over the study area.

Then we considered the block co-kriging error variances calculated from the same co-regionalization model as an estimator of the error on the mean value of the soil property. The validation of the ordinary co-kriging was done by comparing the true measurements with the predicted values obtained from a leave-one-out cross-validation. The error variance given by the co-regionalization model over the whole study area was first compared with the mean square error deduced from the crossvalidation.

To evaluate more precisely if the model can predict the local uncertainty, we built an accuracy plot (Goovaerts, 1999) that allowed us to compare the estimated and the observed fractions of the true values falling into a series of $p$-probability intervals (PI) bounded by $(1-p) / 2$ and $(1+p) / 2$ quantiles and denoted below as A. These probability intervals can be constructed for each $p$. As an example, under the assumption that $Z_{1}$ is Gaussian, the 95\%-probability interval $P I 95$ that satisfies $\operatorname{Pr}\left\{Z_{1}\left(\boldsymbol{u}_{0}\right) A\right\}=95 \%$ will be (Cressie, 1991)

$$
P I_{95} \equiv\left(Z_{1}\left(\boldsymbol{u}_{0}\right)-1.96 \sigma_{E}\left(\boldsymbol{u}_{0}\right), Z_{1}\left(\boldsymbol{u}_{0}\right)+1.96 \sigma_{E}\left(\boldsymbol{u}_{0}\right)\right)
$$


In this example, $95 \%$ is the estimated fraction of the true values falling into $P I_{95}$. It was compared with the observed fraction; that is, the proportion of true measurements falling within $P I_{95}$. Finally, a scattergram of the estimated versus observed fractions for different $p$ allowed us to verify that the spatial model provided a good estimator of the local error variance. Having verified that, it was then possible to use the block kriging error variance estimated by Equation (7) as an estimation of the error on the mean value of the soil property. This error was expressed after the two complementary error indicators, namely, RMSE and the determination coefficient $\left(R^{2}\right)$, thus providing a measure of the absolute and relative error, respectively.

For computing the latter, it was first necessary to calculate the variance of the within-block mean values $\left(Z_{1}(v(\boldsymbol{u}))\right.$ over the spatial domain V (the dispersion variance) (Wackernagel, 1995). It was shown by Wackernagel (1995) that dispersion variance can be calculated from the variograms of the model with the following expression:

$$
\sigma^{2}(v / V)=\bar{\gamma}(V, V)-\bar{\gamma}(v, v)
$$

The theoretical determination of the dispersion variance reduces to the computation of the variogram integrals $\bar{\gamma}(V, V)$ and $\bar{\gamma}(v, v)$ associated with the two supports $v$ and $V$. In practice, this is done by averaging the variogram values of all the pairs of points obtained by a discrete gridding of $v$ and $V$.

To investigate the impact of block size on the clay content predictions, block co-kriging was applied with different block sizes $(50,100,250$ and $500 \mathrm{~m})$. We examined both the absolute performances measured by error variance and RMSE and the relative performances measured by the coefficient of determination $R^{2}$. To calculate the latter, the two terms of the dispersion variance (variogram integrals $\bar{\gamma}(V, V)$ and $\bar{\gamma}(v, v)$ of Equation (9)) were estimated from the co-regionalization model with a block discretisation of 10 and $1 \mathrm{~m}$, respectively.

\section{Results}

\section{Preliminary results}

Figure 3(a,b) shows the distributions of the measurements of clay contents and of $\log \log \mathrm{CR}_{2206}$, respectively. A large variability in clay contents was observed over the study area (Figure 3a), as previously shown (Lagacherie et al., 2008). Although the two distributions (Figure 3a,b) appeared as global bell-shapes, they were too dis-symmetric to be strictly considered as normally distributed. Figure 3(c) shows that clay contents measurements were linearly correlated with $\log \log \left(\mathrm{CR}_{2206}\right)$ with a coefficient of determination that is slightly less than in Lagacherie et al. (2008) ( $R^{2}=0.55$ and 0.58 , respectively) because of the addition of new sites.

To verify that the cross-variogram is an appropriate tool for describing the co-variation of clay contents and $\log \log \mathrm{CR}_{2206}$ over the study area, it was first necessary to examine the pair of the cross-covariance function (Wackernagel, 1995, p. 133).
Figure 4 shows that this cross-covariance function is truly an even function, with no delay or spatial shift effect, which means that no information is lost by using the cross-variogram instead of the cross-covariance.

\section{The co-regionalization model}

The linear co-regionalization model was built for the pair 'clay content' and ' $\log \log \mathrm{CR}_{2206}$ ' from the set of 137 bare-soil field sites at which these two variables were available. To reduce computing costs, we sampled one row and one colunm from every two in the original HYMAP image. The two direct semi-variograms were first modelled as linear combinations of two selected basic structures (spherical $265 \mathrm{~m}$ and spherical $2000 \mathrm{~m})$. The same basic structures were then fitted to the cross-semi-variogram under the positive semi-definite constraint (Goovaerts, 1997).

Figure 5 shows the fitted linear model of co-regionalization. The model is as follows:

$$
\begin{array}{ccccc}
\gamma_{\text {clay-clay }} & \gamma_{\text {clay }}-\mathrm{CR}_{2206} & \\
\gamma_{\mathrm{CR}_{2206}-\text { clay }} & \gamma_{\mathrm{CR}_{2206}}-\mathrm{CR}_{2206} & \\
& & & \\
3693 & -3.786 & & \\
-3.786 & 0.0110 & \text { Sph } & \frac{\boldsymbol{h}}{265} \\
& & & \\
& 1872 & -5.339 & \text { Sph } & \frac{\boldsymbol{h}}{2000}
\end{array},
$$

where Sph $\frac{\boldsymbol{h}}{265}$ and Sph $\frac{\boldsymbol{h}}{2000}$ are the basic spherical models with ranges 265 and $2000 \mathrm{~m}$, respectively.

This model has no nugget effect. The diagonal elements and the determinants of the two co-regionalization matrices are all positive, which means that the linear model of co-regionalization is strictly conditionally negative definite (in the variogram).

Figure 5 shows that the models fit well to the data. The large range structure (spherical $2000 \mathrm{~m}$ ) of the $\log \log \mathrm{CR}_{2206}$ semivariogram has a greater relative importance than that of the clay content semi-variogram, which prevents the application of an intrinsic co-regionalization model.

\section{Punctual co-kriging}

A punctual co-kriging with cross-validation was performed over the region. Because co-kriging from the whole set of sites with hyperspectral data would require too much computing time, subsets of sites were locally selected to represent optimally the spatial structure of the hyperspectral measurements in the neighbourhood of the prediction location. The co-kriging procedure took into account only (i) all of the sites located less than $400 \mathrm{~m}$ from the prediction location and (ii) a sample of the sites located between 400 and $1500 \mathrm{~m}$ made by sampling each neighbouring bare-soil field at $15 \%$ of the sites, which were randomly selected. All of these parameters were fixed after a 

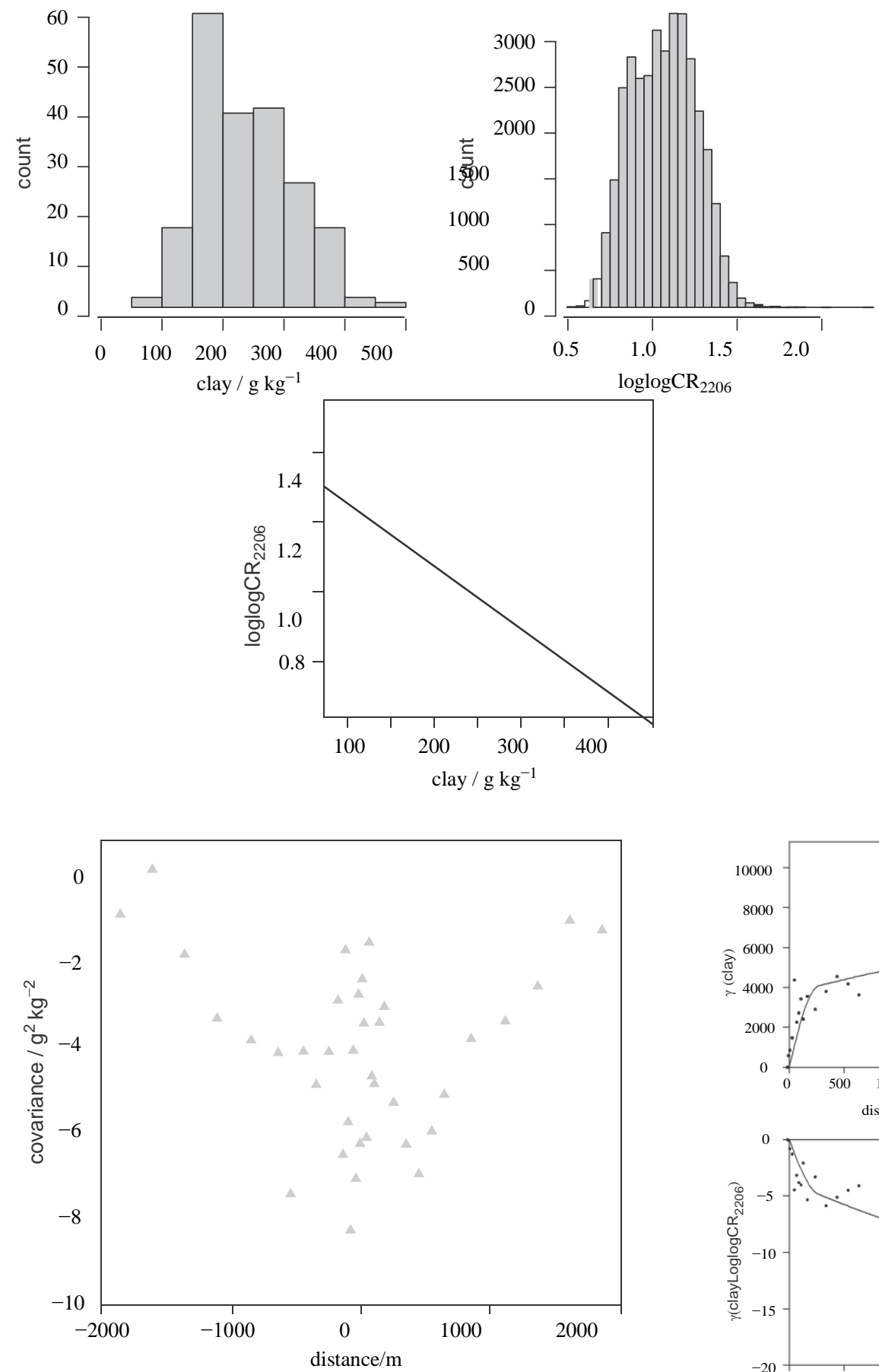

Figure 4 Cross-covariance function (grey triangles) and variogram (black dots) for clay content $\left(Z_{1}\right)$.

trial-and-error procedure, which sought an acceptable compromise between the quality of interpolation and computing cost.

A leave-one-out cross-validation was performed over the set of 200 sites with clay content measurements to obtain a set of observed estimation errors that were compared with the errors

Figure 3 Data distributions and linear relationship: (a) distribution of clay content measurements, (b) distribution of $\log \log \mathrm{CR}_{2206}$, (c) linear relationship between clay content and $\log \log$

$\mathrm{CR}_{2206 .}$
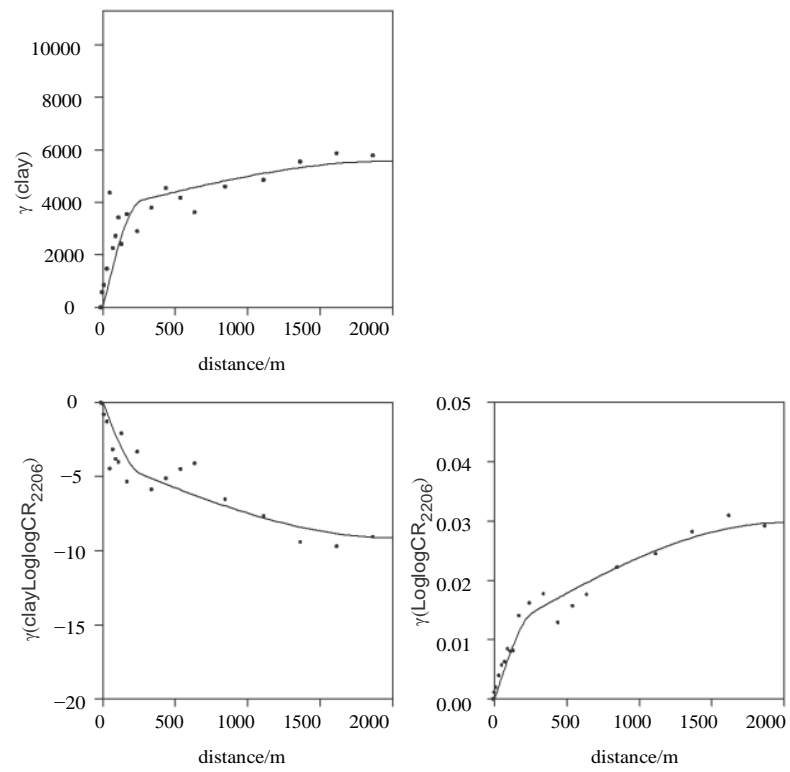

Figure 5 The linear model of co-regionalization for the pair 'clay content' and ' $\log \log \mathrm{CR}_{2206}$ '.

estimated by the co-kriging procedure. The result was that the error variance calculated globally over the 200 sites $\left(2473 \mathrm{~g}^{2}\right.$ $\mathrm{kg}^{-2}$, and $\mathrm{RMSE}=50 \mathrm{~g} \mathrm{~kg}^{-1}$ ) was close to that deduced from the cross-validation outputs (2606 $\mathrm{g}^{2} \mathrm{~kg}^{-2}$, and RMSE $=51 \mathrm{~g} \mathrm{~kg}^{-1}$ ) 


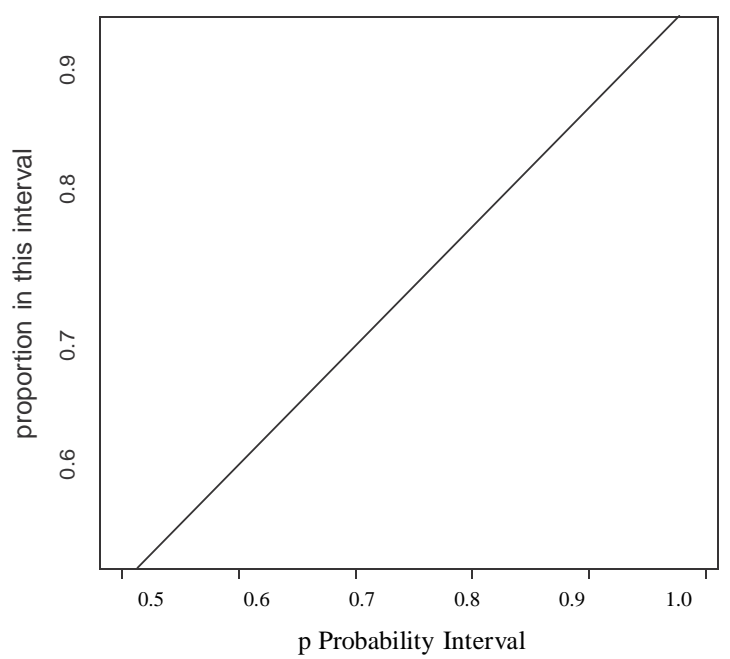

Figure 6 Plots of the true clay content values falling within probability intervals estimated by co-kriging (accuracy plot).

with, however, a slight under-estimation of the errors. It must be noted that the error variance of co-kriging was substantially smaller than that of ordinary kriging $\left(3567 \mathrm{~g}^{2} \mathrm{~kg}^{-2}\right.$, RMSE $=$ $60 \mathrm{~g} \mathrm{~kg}^{-1}$ ), which revealed the added-value of the hyperspectral data.

To evaluate more precisely if the model could predict the local uncertainty, we built an accuracy plot (Figure 6) following the procedure described above. A perfect modelling of local uncertainty would mean that, over the study area, $p \%$ of the $p$-prediction intervals given by the model would include the true value of clay content, which is represented by the $1: 1$ line in Figure 5. We were fairly close to this situation (Figure 6), but there was an under-estimation of the local uncertainty, mostly for p-prediction intervals ranging from 0.75 to 0.85 . Finally, it can be concluded that the co-regionalization model shown in Figure 5 and Equation (10) provided an accurate estimate of the prediction errors for punctual predictions and, consequently, for the block predictions of block means. The latter will be considered in the following section.

\section{Block co-kriging}

Block co-kriging was applied over the study area with the same rules as described to define the spatial neighbourhood of data from which the interpolations are performed. Again, the error variance estimated by the block co-kriging procedure was used as an estimator of the true error. Four situations were distinguished in the study area: predicted blocks (i) close to clay content measurements and hyperspectral data $(\leq 200 \mathrm{~m})$; (ii) close to clay content measurements and far from hyperspectral data $(>200 \mathrm{~m})$; (iii) far from clay content measurements and close to hyperspectral data; and (iv) far from clay content measurements and from hyperspectral data. This classification allowed us to take into account the spatial variation of error related to the local data configurations.

Table 1 shows the performances of the block co-kriging for these four situations with a $100-\mathrm{m}$ block size. As expected, there was a significant decrease of performance with the distance to the data source. These results also showed the usefulness of the hyperspectral data, which improved the predictions where the sites with clay content measurements were close $\left(\mathrm{RMSE}=43 \mathrm{~g} \mathrm{~kg}^{-1}\right.$ compared with $\mathrm{RMSE}=49 \mathrm{~g} \mathrm{~kg}^{-1}$ ) and limited the degradation of the performances where the blocks were located far from any sites with clay content measurements (RMSE $=53 \mathrm{~g} \mathrm{~kg}^{-1}$ compared with RMSE $=58 \mathrm{~g} \mathrm{~kg}^{-1}$ ). Finally, the global error of the $100-\mathrm{m}$ block predictions estimated over the whole area remained fairly large $\left(\mathrm{RMSE}=49 \mathrm{~g} \mathrm{~kg}^{-1}\right.$ ). However, a significant part of this error came blocks located more than $200 \mathrm{~m}$ from any data from

$\left(\mathrm{RMSE}=58 \mathrm{~g} \mathrm{~kg}^{-1}\right)$, which corresponded to urban or forest areas where it was not possible to sample or find any cultivated (bare) fields with hyperspectral data. Removing these areas significantly decreased the global error ( $\mathrm{RMSE}=46 \mathrm{~g} \mathrm{~kg}^{-1}$ ). In the following, only the first three situations will be considered, as they are together more representative of the situations targeted in this study.

The performances of the predictions for different block sizes are presented in Table 2 for the whole area without considering the $19 \%$ urban or forest areas. The estimation error (RMSE) globally decreased as the spatial resolution of predictions (the block size) increased. However, this decrease was moderate between the 50and $100-\mathrm{m}$ resolution, even resulting in a decrease of the ratio of the explained variance measured by $R^{2}$. These results can be explained by the still large spatial autocorrelations for the lag <250 m exhibited by the co-regionalization model (Figure 5), which strongly limited the decrease of variance error that should have been observed if the sites were independent. Finally, for spatial resolutions less than $100 \mathrm{~m}$, at which the block size effect did not play a significant role in decreasing error, it was possible

Table 1 Estimated error variances (RMSE) of 100-m block prediction of clay contents for different data situations

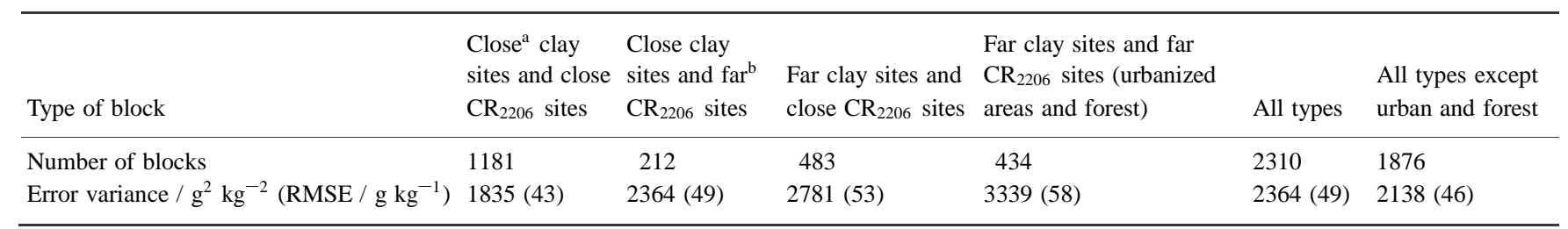


${ }^{\mathrm{a}}$ Close $=<200 \mathrm{~m}$

${ }^{\mathrm{b}} \mathrm{Far}=>200 \mathrm{~m}$. 
Table 2 Estimated performances of the block co-kriging procedure for different spatial resolutions (urban and forest areas excluded)

\begin{tabular}{llllr}
\hline Block size & 50 & 100 & 250 & 500 \\
\hline Numbers of blocks & 9707 & 1876 & 372 & 90 \\
$\begin{array}{l}\text { Dispersion variance / } \\
\quad \mathrm{g}^{2} \mathrm{~kg}^{-2}\end{array}$ & 4835 & 4263 & 2868 & 1828 \\
$\begin{array}{l}\text { Error variance } / \mathrm{g}^{2} \\
\quad \mathrm{~kg}^{-2} \mathrm{RMSE} / \mathrm{g} \mathrm{kg}^{-1}\end{array}$ & $2446(49)$ & $2138(46)$ & $1083(33)$ & $473(22)$ \\
$R^{2}$ & 0.54 & 0.49 & 0.62 & 0.74 \\
\hline
\end{tabular}

to map half of the total variability of the clay content. For coarser resolutions, the prediction errors were small, and the variability mapped by the block co-kriging procedure was large.

Figure 7 shows images of clay content obtained for different resolutions (first row) and the corresponding error maps. All of the images showed a global increase of clay content from the north to the south of the area. This is probably the effect of the parent material, the Pliocene fluvial deposits, being more clayey than the Miocene marine sediments and its derived colluvions and alluvions. At the finest spatial resolutions (50 and $100 \mathrm{~m}$ ), it was possible to see more detailed spatial patterns that could represent a relief effect. However, as shown by the error estimations for these resolutions (Table 2), the density of data and the quality of the relation between the clay content and the hyperspectral covariable (Lagacherie et al., 2008) were not sufficient to successfully map this effect. Finally, the error maps showed that the error decrease observed in Table 2 was associated with a strong decrease of the error variability, especially for resolutions 250 and $500 \mathrm{~m}$. At these resolutions, the blocks became large enough to include systematically clay content data and bare-soil fields, which strongly diminished and homogenized the prediction error.

\section{Discussion}

This study aimed to investigate how hyperspectral imagery data available for a set of fields scattered within a study region could help in mapping soil properties over a region at spatial resolutions compatible with those of normal DSM applications. We also considered a set of sites that had laboratory measurements of the soil properties available. We provide an example of the mapping of clay content over a very heterogeneous area located in the south of France.

Block co-kriging was a suitable procedure for both interpolating and spatially aggregating the available input data to produce medium and coarse resolution maps (from 50 to $500 \mathrm{~m}$ ) of clay content. Although some early applications of co-krigring to the
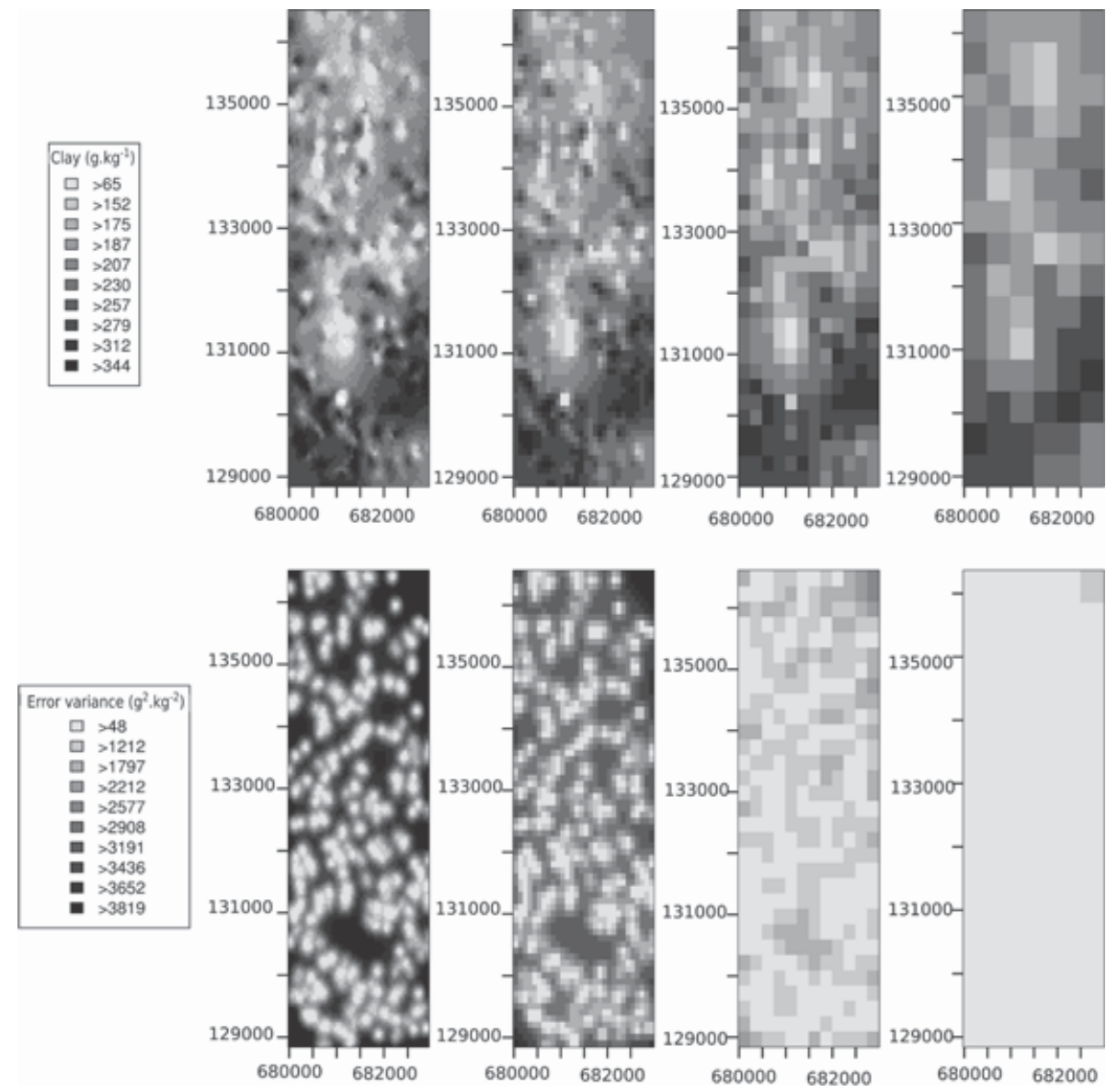

Figure 7 Images of clay content obtained for different resolutions (first row) and images of error variance (second row). 
mapping of soil properties can be found in the literature (Stein \& Corsten, 1991; Odeh et al., 1995), co-kriging has not been used widely in further DSM studies. This may change in the future with the increasing use in DSM of soil sensing covariates such as $\mathrm{CR}_{2206}$ that will be well correlated with a soil property but not exhaustively available in the study area. It must be noted that this procedure can only be applied if an intrinsic or a linear co-regionalization model can be fitted to satisfy the condition of definite positive variogram matrix.

Block predictions of soil properties are not easy to validate because this requires a denser spatial sampling than is required for validating the point predictions. To overcome this problem partially, we proposed first to verify by cross-validation that the co-regionalization model provided a good estimator of the prediction error at punctual sites and then to consider whether the block prediction errors computed from the same coregionalization model can approximate the unavailable observed error satisfactorily. As well as reducing the validation costs, the great advantage of such a procedure is to provide several images of the same spatial variability (Figure 7) that represent different compromises between accuracy and spatial resolution matching different users' requirements. However, this validation procedure does not match the usual recommendations for validating DSM results (Lagacherie, 2008). It should therefore be completed by validations from independent samples (Brus et al., 2011). This would require an affordable spatial sampling design that would provide accurate local estimations of block prediction errors and represent the study area well, which would require, respectively, a minimum number of sites within a block and a sufficient amount of validation blocks. Recent advances in soil property measurement technologies (Adamchuk \& Viscarra Rossel et al., 2010) should greatly help in fulfilling these requirements.

We found that the hyperspectral image improved the prediction of clay contents substantially in spite of a moderate correlation between clay content and the hyperspectral covariable $\left(R^{2}=0.58\right)$ and a limited coverage of the study area (3.5\%). The former will be ameliorated by improving the correlations thanks to the use of multivariate regression techniques (Ben-Dor et al., 2008; Gomez et al., 2008; Stevens et al., 2010). Progress on the latter will concern either a defined choice of the flying period to increase the chances of getting bare soil surfaces or the use of signal processing algorithms such as spectral un-mixing techniques (Chabrillat et al., 2002; Bartholomeus et al., 2011) or 'blind source separation' algorithms (Ouerghemmi et al., 2011) that would allow us to extend the hyperspectral estimations of soil properties to partially vegetated soil surfaces.

\section{Conclusions}

The key outputs from this study can be summarized as follows. Block co-kriging is a suitable procedure for using as DSM inputs high-resolution and scattered data such as those produced by hyperspectral imagery. The unavailability of suitable spatial sampling for estimating errors on block mean soil properties can be partially overcome by using the error variance given by a DSM model previously validated at punctual sites. More research is needed on specific spatial sampling for validating block means estimations from independent samples. A DSM model can produce various maps that represent different compromises between prediction accuracy and spatial resolution. Using hyperspectral data significantly increases the accuracy of the mean clay content estimations. This result should, however, be improved by increasing the accuracy of the hyperspectral indicator and extending the surface covered by hyperspectral data.

\section{Acknowledgements}

This research was supported by INRA, IRD and the French National Research Agency (ANR) (ANR-08-BLAN-0284-01). We are indebted to Dr Steven M. de Jong, Utrecht University in the Netherlands, and to Dr Andreas Mueller of the German Aerospace Establishment (DLR) in Wessling, Germany, for providing the 2003 HyMap images used in this study. We are also indebted to Yves Blanca, IRD-UMR LISAH Montpellier, for the soil sampling in 2009 over the vineyard plain of Languedoc.

\section{References}

Adamchuk, V.I. \& Viscarra Rossel, R.A. 2010. Development of on-the-go proximal sensing systems. In: Proximal Soil Sensing, Progress in Soil Science, Volume 1 (eds R.A. Viscarra Rossel, A.B. McBratney \& B. Minasny), pp. 15-28. Springer, Dordrecht, Heidelberg.

Bartholomeus, H., Kooistra, L., Stevens, A., Van Leeuwen, M., Van Wesemael, B., Ben-Dor, E. et al. 2011. Soil organic carbon mapping of partially vegetated agricultural fields with imaging spectroscopy. International Journal of Applied Earth Observation \& Geoinformation, 13, $81-88$.

Beis1, U. 2001. Correction of bidirectional effects in imaging spectrometer data. PhD thesis, Remote Sensing Series 37, RSL, University of Zurich, Zurich.

Ben-Dor, E., Taylor, R.G., Hill, J., Demattê, J.A.M., Whiting, M.L., Chabrillat, S. et al. 2008. Imaging spectrometry for soil applications. Advances in Agronomy, 97, 321-392.

Brus, D.J., Kempen, B. \& Heuvelink, G.B.M. 2011. Sampling for validation of digital soil maps. European Journal of Soil Science, 62, 394-407.

Chabrillat, S., Goetz, A.F.H., Olsen, H.W. \& Krosley, L. 2002. Use of hyperspectral images in the identification and mapping of expansive clay soils and the role of spatial resolution. Remote Sensing of Environment, 82, 431-445.

Clark, R.N. \& Roush, T.L. 1984. Reflectance spectroscopy: quantitative analysis techniques for remote sensing applications. Journal of Geophysical Research, 89, 6329-6340.

Cressie, N.A.C. 1991. Statistics for Spatial Data. John Wiley \& Sons, New York.

Gertner, G., Wang, G., Andersol, A.B. \& Howard, H. 2007. Combining stratification and up-scaling method-block cokriging with remote sensing imagery for sampling and mapping an erosion cover factor. Ecological Informatics, 2, 373-386.

Gomez, C., Lagacherie, P. \& Coulouma, G. 2008. Continuum removal versus PLSR method for clay and calcium carbonate content estimation 
from laboratory and airborne hyperspectral measurements. Geoderma, 148, $141-148$.

Goovaerts, P. 1997. Geostatistics for Natural Resources Evaluation, Applied Geostatistics Series. Oxford University Press, Oxford.

Goovaerts, P. 1999. Geostatistical modeling of uncertainty in soil science. Geoderma, 103, 3-26.

Grunwald, S. 2009. Multi-criteria characterization of recent digital soil mapping and modeling approaches. Geoderma, 152, 195-207.

ISSS, ISRIC, FAO 1998. World Reference Base for Soil Resources. World Soil Resources Report 84, FAO, Rome.

Jenny, H. 1941. Factors of Soil Formation, a System of Quantitative Pedology. McGraw-Hill, New York.

Jolivet, C., Arrouays, D., Boulonne, L., Ratie, C. \& Saby, N. 2006. Le réseau de mesures de la qualité des sols de France (RMQS), Etat d'avancement et premiers résultats. Etude et Gestion des Sols, 13, $149-164$.

Lagacherie, P. 2008. Digital soil mapping: a state of the art. In: Digital Soil Mapping with Limited Soil Data (eds A. Hartemink, A.B. McBratney \& L. Mendonça-Santos), pp. 3-14. Springer, Dordrecht, Heidelberg.

Lagacherie, P., Baret, F., Feret, J.B., Madeira Netto, J.S. \& RobbezMasson, J.M. 2008. Clay and calcium carbonate contents estimated from continuum removal indices derived from laboratory, field and airborne hyper-spectral measurements. Remote Sensing of Environment, 112, 825-835.

Leenhardt, D., Voltz, M., Bornand, M. \& Webster, R. 1994. Evaluating soil maps for prediction of soil water properties. European Journal of Soil Science, 45, 293-301.

Matheron, G. 1971. The Theory of Regionalised Variables and its Applications. Ecole des Mines, Fontainebleau.

McBratney, A.B., Mendonça Santos, M.L. \& Minasny, B. 2003. On digital soil mapping. Geoderma, 117, 3-52.

Odeh, I.O.A., McBratney, A.B. \& Chittleborough, D.J. 1995. Further results on prediction of soil properties from terrain attributes: heterotopic cokriging and regression-kriging. Geoderma, 67, 215-226.
Ouerghemmi, W., Gomez, C., Nacer, S. \& Lagacherie, P. 2011. Applying blind source separation on hyperspectral data for clay content estimation over partially vegetated surface. Geoderma, 163, 227-237.

Richter, R. 1996. Atmospheric correction of DAIS hyperspectral image data. Computers \& Geosciences, 22, 785-793.

Richter, R. \& Schläpfer, D.A. 2000. A unified approach to parametric geocoding and atmospheric/topographic correction for wide FOV airborne imagery. Part 2: atmospheric correction. In Proceedings 2nd International EARSeL Workshop on Imaging Spectroscopy, Enschede, 11-13 July 2000.

Sanchez, P., Ahamed, S., Carré, F., Hartemink, A., Hempel, J., Huising, J. et al. 2009. Digital soil map of the world. Science, 325, 680-681.

Schwanghart, W. \& Jarmer, T. 2011. Linking spatial patterns of soil organic carbon to topography - a case study from south-eastern Spain. Geomorphology, 126, 252-263.

Selige, T., Bohner, J. \& Schmidhalter, U. 2006. High resolution topsoil mapping using hyperspectral image and field data in multivariate regression modeling procedures. Geoderma, 136, 235-244.

Stein, A. \& Corsten, L.C.A. 1991. Universal kriging and cokriging as a regression procedure. Biometrics, 47, 575-587.

Stevens, A., Udelhoven, T., Denis, A., Tychon, B., Lioy, R., Hoffmann, L. et al. 2010. Measuring soil organic carbon in croplands at regional scale using airborne imaging spectroscopy. Geoderma, 158, 32-45.

Viscarra Rossel, R.A., Walvoort, D.J.J., McBratney, A.B., Janik, L.J. \& Skjemstad, J.O. 2006. Visible, near-infrared, mid-infrared or combined diffuse reflectance spectroscopy for simultaneous assessment of various soil properties. Geoderma, 131, 59-75.

Viscarra Rossel, R.A., McBratney, A.B. \& Minasny, B. 2010. Proximal Soil Sensing, Progress in Soil Science, Volume 1. Springer, Dordrecht, Heidelberg.

Wackernagel, H. 1995. Multivariate Geostatistics. Springer-Verlag, London. 